\title{
FOUR NEW SPECIES OF PHTHIRACARID MITES (ACARI: ORIBATEI) FROM MALABAR, KERALA, INDIA
}

\author{
M.A. Haq ${ }^{1}$ and Alphonsa Xavier ${ }^{2}$ \\ 1 Department of Zoology, University of Calicut, Kerala 673635, India \\ 2 Department of Zoology, Government Arts \& Science College, Kozhikode, Kerala 673018, India \\ Email: 1 haqma@sancharnet.in; ${ }^{2}$ puthusery@sify.com
}

\begin{abstract}
Four new species of phthiracarid mites, viz., Atropacarus (Hoplophorella) chaliyamensis, A. (H.) crenulus, A. (H.) reticulatus and $A$. (H.) calotropicus are reported from Kerala, India. This is the first report of this genus from southern India. A. (H.) chaliyamensis is characterised by the presence of two lateral carinae as a pair of stumps on the prodorsum which stop abruptly at the middle and the barbed nature of adanal seta $a_{2}$. A. (H.) crenulus possesses an oval prodorsum with slightly pointed tip and an elongated sensillus with a round fan-shaped projection towards the tip with crenulation along its anterior margin. Exobothridial seta is absent while seta $a_{2}$ is thin and smooth with pointed tip. In A. (H.) reticulatus lateral carina is well developed which bulges outwards towards the middle of prodorsum. Prodorsal integument shows a number of longitudinal striations which cross one over the other presenting a highly reticulated appearance. Rostral seta is thick, lamellar seta is elongated while notogastral setae are bare. In $\mathrm{A}$. (H.) calotropicus, prodorsum is oblong with rounded rostral apex and without lateral carina. Prodorsum exhibit wrinkled ornamentation while notogaster is densely foveolate. Rostral seta is barbed while notogastral setae $c_{1}, d_{1}$ and $e_{1}$ appear foliate with uniform thickness.
\end{abstract}

\section{KEYWORDS}

Atropacarus (Hoplophorella) calotropicus sp. nov., Atropacarus (Hoplophorella) chaliyamensis sp. nov., Atropacarus (Hoplophorella) crenulus sp. nov., Atropacarus (Hoplophorella) reticulatus sp. nov., Kerala, Malabar, new species, phthiracarid mites

\section{AbBreviations}

a, h, m - infracapitular setae; a', a" - antilateral setae; acm anterior centromedian seta; ad - adanal; ag - aggenital seta; am - antero median seta; an - anal; bo - bothridium; cha cheliceral seta a; chb - cheliceral seta b; $\mathrm{c}_{1}, \mathrm{C}_{2}, \mathrm{c}_{3}$ - setae of first notogastral segment c; cm - centromedian seta; d', d" dorsal setae; $d_{1}, d_{2}, d_{2}$ - setae of second notogastral segment $\mathrm{d}$; e - famulus; $\mathrm{e}_{1}, \mathrm{e}_{2}$ - setae third notogastral segment e; ex exobothridial seta; $f_{1}, f_{2}$ - setae of fourth notogastral segment $\mathrm{f} ; \mathrm{ft}$ ', $\mathrm{ft}$ " - fastiginal setae; $\mathrm{g}$ - genital; $\mathrm{g}_{1}-\mathrm{g}_{9}$ - genital setae; $\mathrm{h}_{1}$, $h_{2}, h_{3}$ - setae of fifth notogastral segment $h$; in - interlamellar seta; inf - inferior seta; it', it" - iteral setae; l', l" - lateral setae; le - lamellar seta; $m$ - monotropic seta; p', p" - proral setae; $\mathrm{ps}_{1}, \mathrm{ps}_{2}, \mathrm{ps}_{3}$ - setae of sixth notogastral segment ps; pl', pl" primilateral setae; $p v^{\prime}, p v "$ - primiventral setae; ro - rostral seta; ss - sensillus; su/s - subunguinal seta; tc', tc" - tectal setae; u', u" - unguinal setae; ul', ul" - unguinal lateral setae, v', v" - ventral setae; w, j, s - solenidion omega, phi, sigma

Phthiracarid mites constitute one of the most important group of oribatid mites, rendering substantial removal of organic materials by their voracious and xylophagous feeding habit. While feeding they bore into wood pieces, form tunnels and galleries in the wood and transform the excavated wood into energy rich faecal pellets. Such rare ability of this group of mites raised their status as potential biodegraders of higher plant materials (Dinsdale, 1974; Haq, 1984, 1987, 2003; Haq \& Konikkara, 1988; Edsberg \& Hagwar, 1999). However, knowledge on these group of mites from India is practically meagre. Hence better chances of utilisation of these mites is seriously warranted particularly in an agricultural country like India.

The genus Atropacarus Ewing, 1917 is characterised by fifteen pairs of notogastral setae, nine pairs of genital setae and five pairs of anoadanal setae. Seta $a d_{2}$ slightly away from paraxial margin.

The type materials are deposited at the Division of Acarology, Department of Zoology, University of Calicut, Kerala, India.

All measurements are given in $\mu \mathrm{m}$.

\section{Atropacarus (Hoplophorella) chaliyamensis sp. nov.} (Figs. 1-12)

\section{Material Examined}

Holotype: Female, 20.v.2001, from unidentified wooden pieces, Chaliyam, Kerala, India, coll. M.A. Haq.

Paratype: 20 females, 3 males, same information as above.

\section{Etymology}

Species name pertains to the place of collection, the Chaliyam Beach.

\section{Diagnosis}

Colour: Wheat brown.

Prodorsum (Figs. 1 \& 2): Length - 230 (Range 208-236); width 110 (Range 102-116). Prodorsum elongated and flexed medioventrally. Two lateral carinae present as a pair of stumps on the prodorsum which stop abruptly at the middle of prodorsum. Seta ro (Fig. 4) short, blunt, smooth, curved inwards, measures 37 and inserted far below the anterior margin of the rostrum. Seta le (Fig. 5) long, stout, measures 110, barbed half of its length, barbs appear stronger towards the tip. Seta in short reaching 13, thinner than ro, erect and inserted in between le and bo. All prodorsal setae with pronounced insertional points and deeply inserted in the integument. Seta ex thinnest, measuring 29 and inserted near bo. Bothridium (Fig. 3) laterally opened. Sensillus (Fig. 3) long stalked with a length of 66 and 


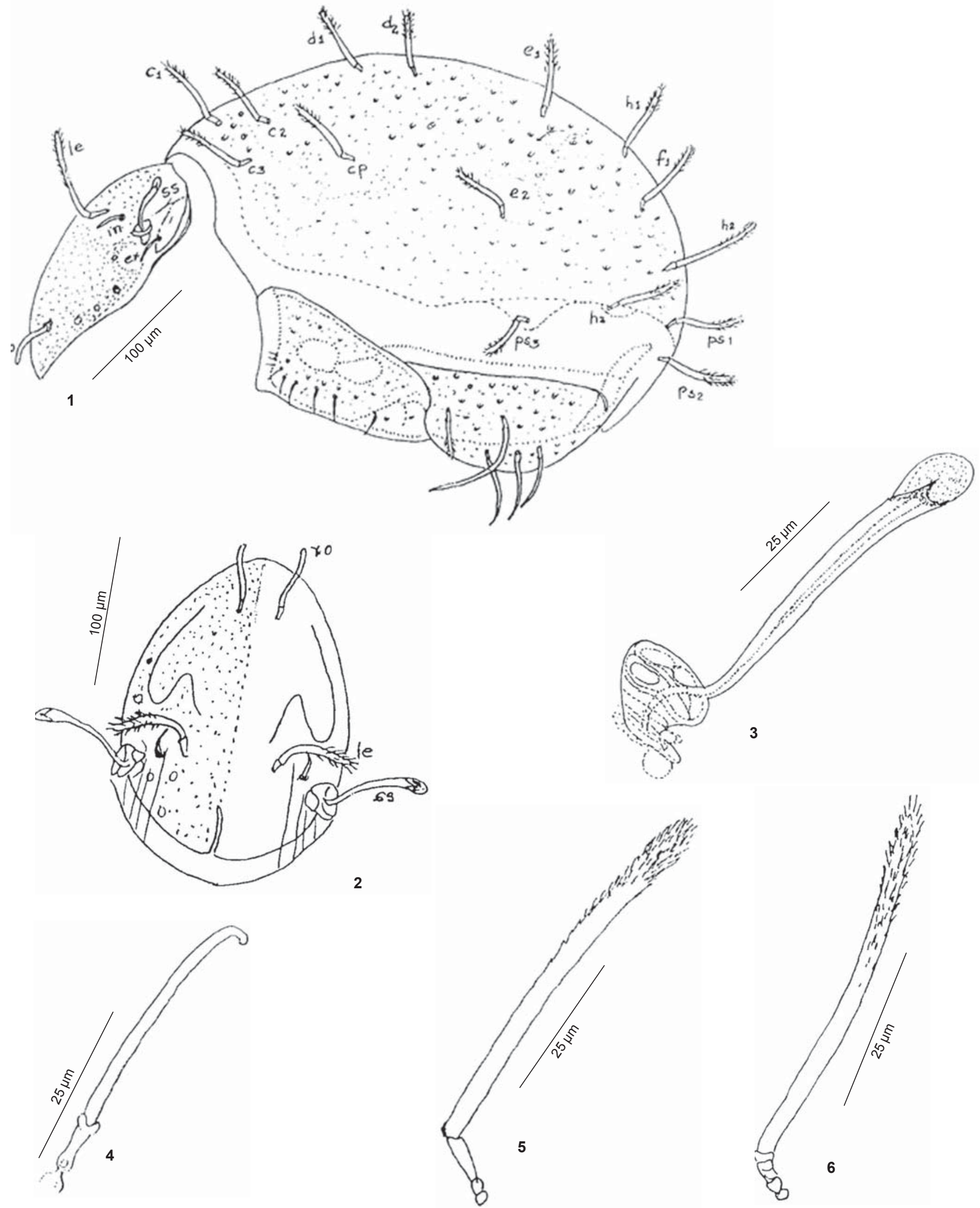

Figures 1-6. Atropacarus (Hoplophorella) chaliyamensis sp. nov. 

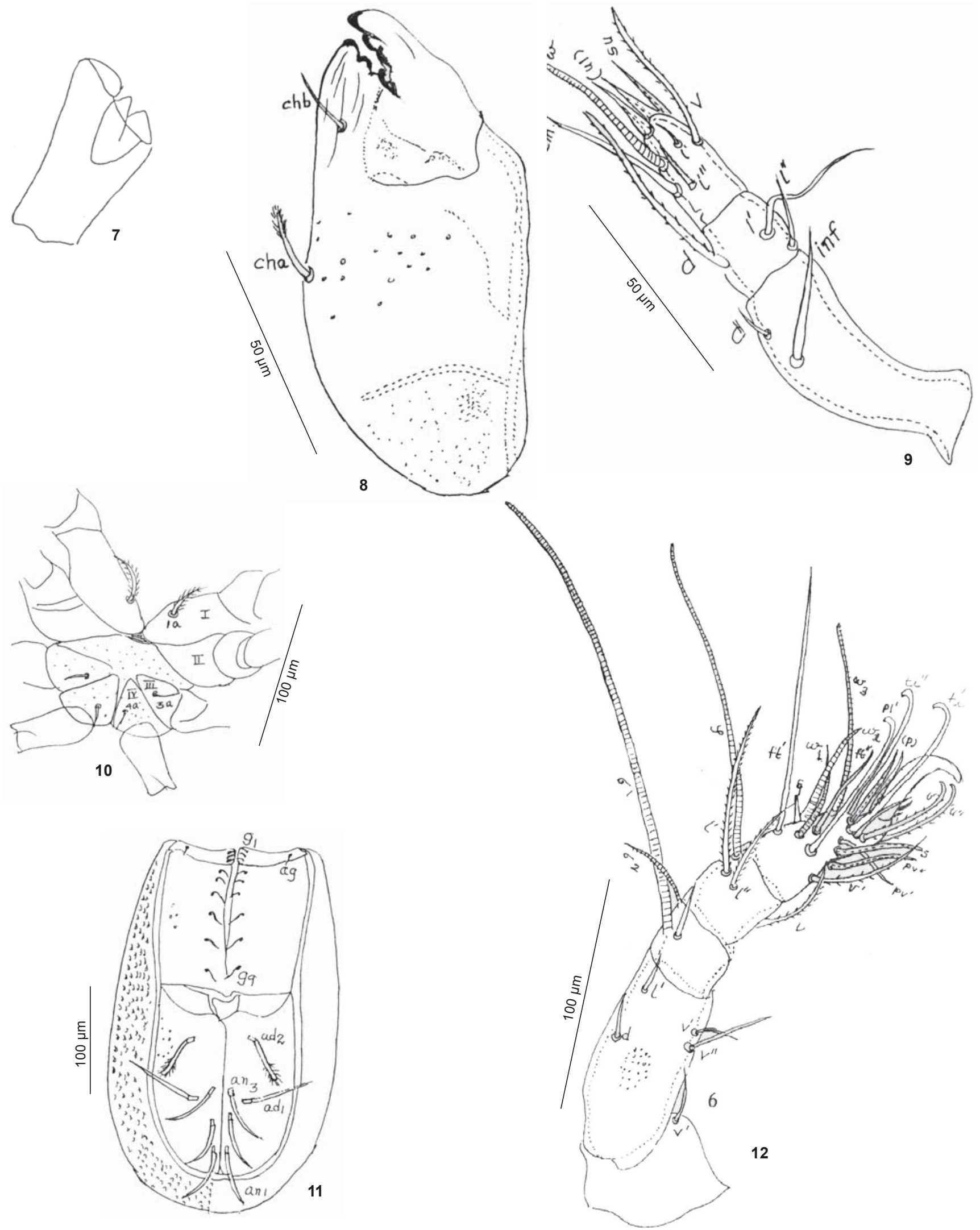

Figures 7-12. Atropacarus (Hoplophorella) chaliyamensis sp. nov.

7 - Rutellum; 8 - Chelicera; 9 - Pedipalp; 10 - Epimeral region; 11 - Genital and ano adanal region; 12 - Leg 1 
gradually dilating to form a club shaped head. Lateral border of prodorsum with scattered foveolae. Postero-lateral margins of prodorsum with vertical striations of varying number which stop abruptly below the level of seta le. Posterior margin of the prodorsum below the level of bo wavy. Entire prodorsal integument punctated.

Notogaster (Fig. 1): Length - 447 (Range 409-457); width - 322 (Range 312-348). Notogaster highly convex with a round posterior border, the extreme posterior apex produced into a caud. Fifteen pairs of setae arranged on the notogaster (Figs. $1 \& 6)$. These setae show variation in length ranging from 57 99, $\mathrm{ps}_{3}$ the shortest $h_{2}$ the longest. Notogastral integument sculptured with round foveoles which follow a regular pattern of arrangement. Foveoles more distinct on the dorsal aspect, but feeble, sparsely arranged and often indistinct along the medio-lateral aspects. Micropunctations present on notogaster interspersed with foveoles. Sclerotisation well along the dorsal and lateral borders of notogaster.

Ventral region: Labiogenal articulation stenarthric. Rutellum (Fig. 7) stout, broad with three notches, the central notch resembles a well developed blunt spine and the two lateral notches broad, the inner notch also produced into a pointed spine. Chelicerae (Fig. 8) broad and stout with punctations on basal portion, each digit with four blunt teeth. Seta $c h b$ smooth while cha with barbs at distal end. Pedipalp (Fig. 9) with a chaetotaxy of 2-3-8. Palpal tarsus with three eupathidia, $u l$ ', $u l$ ' and $s u$, one solenidion, ' $w$ ', one barbed seta and three simple setae. Infracapitular setae smooth and show variation in length, $a$ the longest and barbed. Gnathosomal integument punctated. Epimeral setal formula 1-0-1-1, seta on epimere 1 long, barbed and tapering. Setae on epimeres 3 and 4 almost equal and smooth (Fig. 10). Genital plates (Fig. 11) somewhat rectangular, carrying nine pairs of smooth setae, $g_{1}, g_{2}$ and $g_{3}$ minute. Distance between $\mathrm{g}_{6}, \mathrm{~g}_{7}, \mathrm{~g}_{8}$ and $\mathrm{g}_{9}$ almost equal. Anterior genital setae placed nearer compared to the posterior ones. A pair of small, smooth aggenital setae detected. Genital plates ornamented with small foveoles. Anoadanal plates (Fig. 11) also rectangular with round posterior and concave anterior borders. Each plate bears three smooth, short setae at its inner posterior margin. Two pairs of adanal setae detected, ad long, smooth and inserted at a level between $a n_{2}$ and $a n_{3}$. Seta $a d_{2}$ inserted far anteriorly on the adanal plate. Seta $a d_{2}$ short and barbed distally. Ventral plate lying adjacent to the anoadanal plate also foveolated.

Legs: All legs monodactylous with the claws bearing two spines each, distal spine longer and stouter than proximal spine. Chaetotaxy of leg I (Fig. 12) 1-4-3-4-18. Seta $v$ on trochanter I, smooth and thin. Two solenidia $s_{1}$ and $s_{2}$ present on genu I, the former thicker and longer than the latter, reaching four times its length. Tibia I carries a single solenidion $j$, and three barbed setae $l$ ', $l$ "' and $v$. Tarsus I carries three solenidia $w_{l}, w_{2}$ and $w_{3}$. Famulus $e$ elongated, stump like and situated very near to $w_{l}$. Seta $t c$ ', $t c$ ", $p^{\prime} u^{\prime}$ and $u^{\prime \prime}$ with curved tips. Setae $s, p v ", p^{\prime}$ and $p$ " eupathidic, setae $v^{\prime}, u$ ' and $u$ " provided with a few barbs.

\section{Remarks}

A total of 23 species of Atropacarus (Hoplophorella) have been described so far, as given in the list enclosed. A close scrutiny of the morphological features of the new species $A$. chaliyamensis with other known species of the genus helped to detect its similarity with $A$. (H.) venusta described by Niedbala (1983c) from Uganda in the nature of prodorsal and notogastral setae and in the number and arrangement of epimeral, genital and ano-adanal setae. But on the basis of the following characters, the present species has been assigned a new taxonomic status:

(i) Absence of dorsal carina on prodorsum;

(ii) Barbed nature of seta $a d$;

(iii) Elongated nature of anal setae $a n_{1}-a n_{3}$;

(iv) Possession of palpal setal formula of 2-3-8 instead of 2-2-6 and leg chaetotaxy of 1-4-3-4-18 instead of 1-4-3-4-17;

(v) Seta $s$ present in the new species.

The differences between $A$. (H.) chaliyamensis and $A$. (H.) sundarbanensis are as follows:

(i) Apis of $A$. (H.) chaliyamensis is elongated with a narrow tip (Fig. 1). But aspis of $A$. (H.) sundarbanensis is not as elongated and without a narrow tip;

(ii) Two lateral carine are present as a pair of stumps on the prodorsum which stop abruptly at the middle of the prodorsum in the case of $A$. (H.) chaliyamensis. There is no mention of such a feature in the case of $A$. (H.) sundarbanensis;

(iii) Seta ro of $A$. $(H$.) chaliyamensis is short, blunt, smooth and curved inwards. But seta ro of $A$. (H.) sundarbanensis is moderately long, stout, outwardly directed and pointed;

(iv) Aggenito-genital plats of $A$. (H.) chaliyamensis bears nine pairs of smooth setae with definite pattern of arrangement while A. (H.) sundarbanensis bears only 4 pairs of setae in this region; (v) Rutellum, chelicera, pedipalp, infracapitular setae, epimeral region and leg cannot be compared as these structures of $A$. (H.) sundarbanensis have not been described.

\section{Atropacarus (Hoplophorella) crenulus sp. nov.} (Figs. 13-21)

\section{Material Examined}

Holotype: Female, 04.vi.2001, from unidentified drift wood, Chaliyam, Kerala, India, coll. M.A. Haq.

Paratype: 2 females and 1 male, same information as above.

\section{Etymology}

Species name pertains to the crenulated anterior margin of the sensillus.

\section{Diagnosis \\ Colour: Creamy white}

Prodorsum (Figs. 13 \& 14): Length - 208 (Range 202-214); width - 100 (Range 96-105). Prodorsum oval in shape with slightly pointed tip. Seta ro stiff, with slight bent, smooth and inserted slightly away from the rostral apex, measuring 60 in length. Seta le largest among all the prodorsal setae, measuring 90 bearing fine barbs on one side. Seta in small and smooth, 

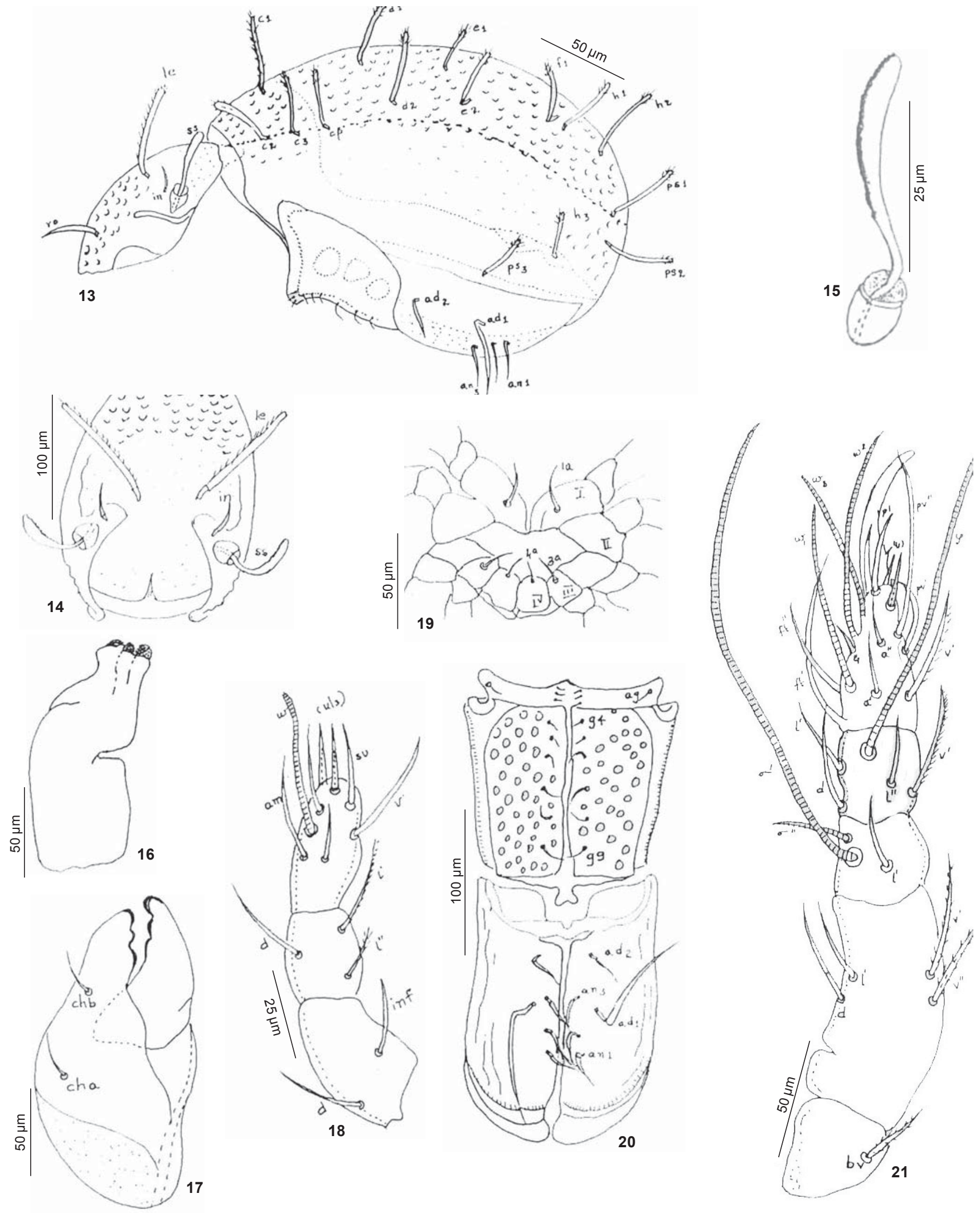

Figures 13-21. Atropacarus (Hoplophorella) crenulus sp. nov.

13 - Lateral view of adult; 14 - Prodorsum; 15 - Bothridium and sensillus; 16 - Rutellum; 17 - Chelicera; 18 - Pedipalp; 19 - Epimeral region; 20 - Genital and ano adanal region; 21 - Leg 1 
measuring 22 and inserted very close to base of bo. Seta ex not visible. Sensillus elongate with a round fan shaped projection towards the tip with crenulation along the anterior margin (Fig. 15). Bothridium cup shaped, directed posteriorly towards the lateral side. Prodorsum exhibits prominent foveolae towards the anterior one third of the tip with sparse and minute punctations towards the posterior region. A thin median ridge extends from the base of the prodorsum to a short distance while lateral carina with a prominent ridge projects towards the centre enclosing bo and in.

Notogaster (Fig. 12): Length - 440 (Range 436-444); width - 300 (Range 294-306). Notogaster globular with rounded posterior end. Ornamentation more pronounced than on prodorsum, especially along the mid dorsal region of notogaster and becoming less prominent laterally. 15 pairs of notogastral setae. Seta $c_{1}$ with fine barbs all along its length, all other setae with fine barbs towards the tip alone. Setae $e_{1}, h_{3}$, and $p s_{3}$ measure 42-50 while others measure 82-92.

Ventral region: Rutellum (Fig. 16) broad and thick with three well developed bent notches of equal size. Chelicerae stout with well developed teeth on both digits. Setae cha and chb smooth and pointed. (Fig. 17). Pedipalp with a chaetotaxy of 23-8, palpal solenidion thick and blunt (Fig. 18). Infracapitulum with three setae $a, h$ and $m$, all simple, smooth with pointed tip. Epimeral setal formula 1-0-1-1. All setae smooth and pointed, but seta of epimere 1 longer than the others (Fig. 19). Each genital plate (Fig. 20) rectangular in shape, carrying the broad and short aggenital plate which in turn carries a minute seta $a g$ at its outer corner. Genital setae $g_{1}-g_{9}$ clearly visible, arranged in a row towards the inner margin, $g_{1}-g_{3}$ much smaller than the others and very closely arranged. Genital plates ornamented with foveoles. Ano-adanal plates broader towards the middle region and with rounded posterior border. Three pairs of anal and two pairs of adanal setae present. Anal setae simple, thin and with pointed tip. $a d_{1}$ much longer than $a d_{2}$, with a $90^{\circ}$ bent towards the base, and with straight pointed tip. Seta $a d$, resembles anal setae. Integument of anoadanal plate with a few wrinkles towards the lateral and basal portion.

Legs: All legs monodactylous, with a stout claw on each tarsal segment. Chaetotaxy of leg I (Fig. 21) 1-4-3-5-15. Seta of trochanter I with a few barbs. Femur I with four setae, $v$ ' and $v$ " with barbs, $d$ and $l$ ' smooth. Genu I carries two solenidia $s_{l}$ and $s_{2} . s_{1}$ very long, thick and pointed towards the tip. $s_{2}$ short and pointed. Tibia I bears five setae, of which $j$ long and blunt solenidion, $v$ 'barbed, others smooth. Tarsus I bears 15 setae including three solenidia $w_{1}, w_{2}$ and $w_{3}$. Famulus $e$ seen close to $w_{2}$. Seta $s$ absent. Claw on the tarsus blunt with a basal ventral tooth.

\section{Remarks}

On comparing the morphological characters of the present specimen with other described species, it shows close similarity with A. (H.) singularis (Sellnick, 1959) in the following characters:

(i) Notogastral setae with barbs towards distal half. (ii) Long and thin nature of anal setae.

(iii) Arrangement of genital setae.

But the present specimen can be distinguished from $A$. (H.) singularis in the following features:

(i) Sensillus with broad tip, crenulated along the anterior margin.

(ii) Seta le with fine barbs on one side

(iii) Absence of seta ex.

(iv) Seta in small and smooth

(v) Seta $\mathrm{ad}_{2}$ thin and smooth with pointed tip

(vi) Difference in leg chaetotaxy; chaetotaxy of leg I in $A$. (H.) singularis 1-4-2-5-18 while that of the present species 1-4-3-515.

These features justify the erection of a new taxon.

\section{Atropacarus (Hoplophorella) reticulatus sp. nov.}

(Figs. 22-31)

\section{Material Examined}

Holotype: Female, 14.vi.2001, secondary forest behind Pareeksha Bhavan, Calicut University Campus, Kerala, India, coll. Alphonsa Xavier.

Paratype: 3 females, same information as above.

\section{Etymology}

Species name pertains to the reticulated appearance of prodorsal integument

\section{Diagnosis \\ Colour: Creamy white.}

Prodorsum (Figs. 22 \& 23): Length - 208 (Range 192-208); width - 96 (Range 88-96). Prodorsum elongated with well developed lateral carina which bulges outwards towards the middle of the prodorsum. Rostral apex conical. Seta ro short, thick and foliate towards the tip, inserted away from rostral apex and measuring 36. Seta le longest of all prodorsal setae with uniform thickness, measuring 53. Seta in thin and pointed, 16 long. Seta ex not visible. Bothridium cup shaped with a wide opening. Sensillus (Fig. 25) with long thin pedicel becoming broader towards the tip, crenulated and spinous along the posterior margin. Prodorsal integument provided with a number of longitudinal striations which cross one over the other presenting a highly reticulated appearance; these striations not reach the rostral apex, so that the rostral tip remains smooth.

Notogaster: Length - 380 (Range 368-380); width - 240 (Range 232-240). Notogaster convex with its extreme posterior end produced into a caud. Fifteen pairs of smooth spoon shaped setae (Fig. 24) ranging in size from 40-60. Seta $c_{1}$ the longest and $p s_{3}$ the shortest. Integument of notogaster with fine punctuations and a few foveolae.

Ventral region: Rutellum (Fig. 26) broad and thick with three well-developed notches, the median one triangular while the lateral ones rounded. Chelicerae (Fig. 28) rugose in appearance with four teeth on the fixed digit and three on the movable digit. 

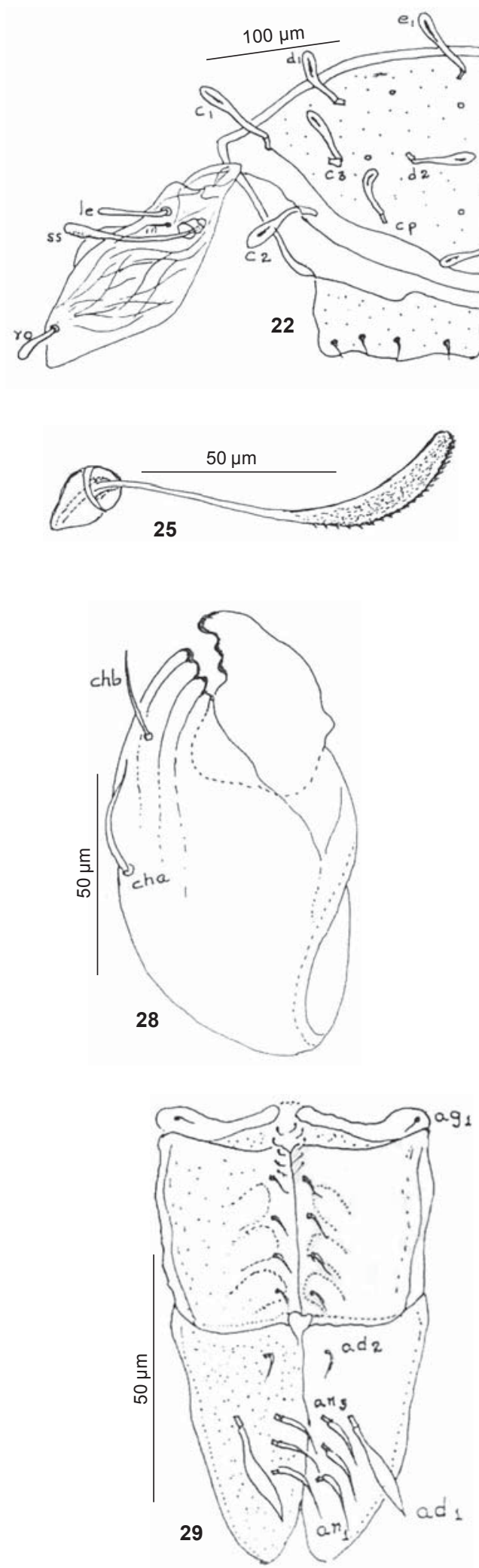
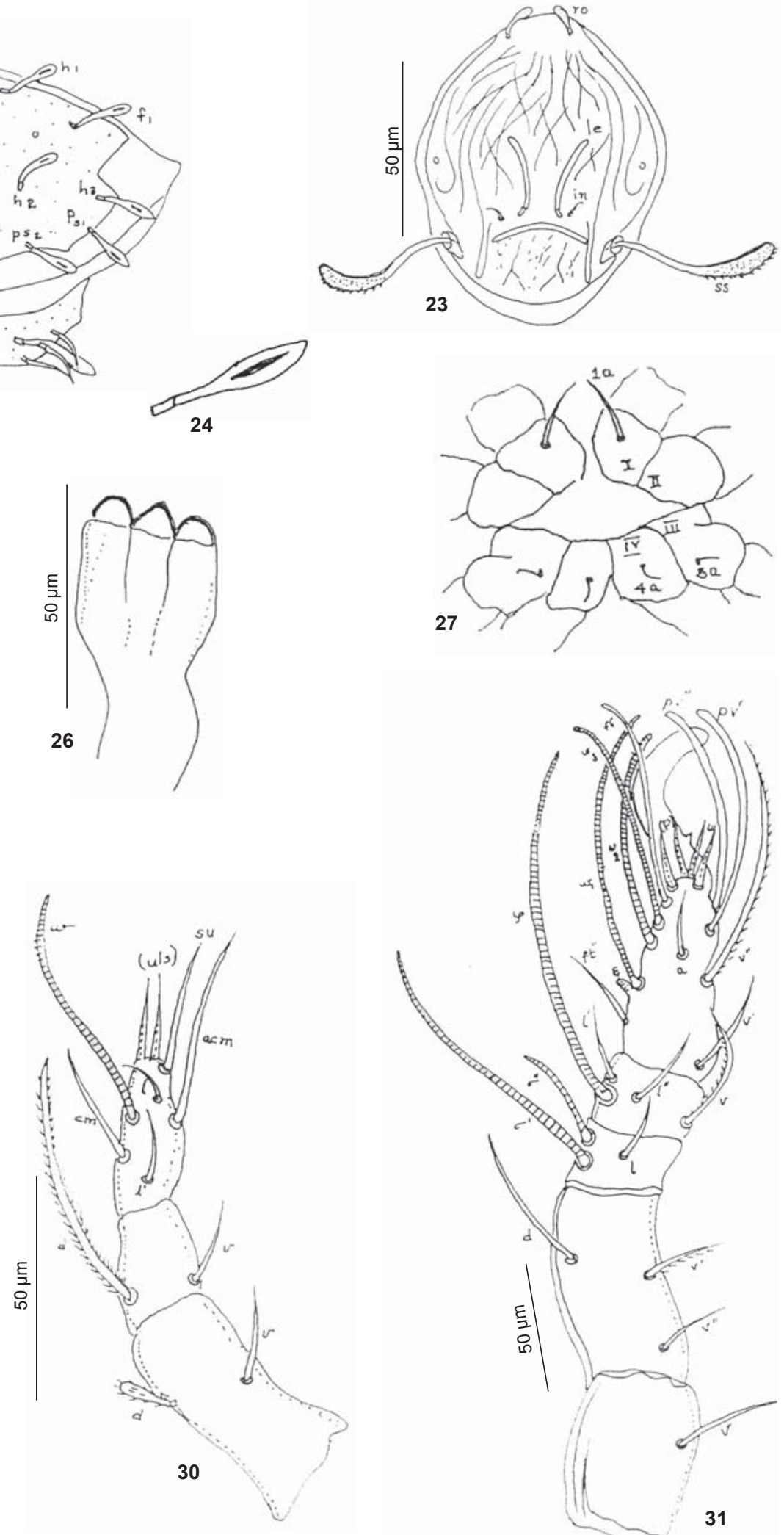

Figures 22-31. Atropacarus (Hoplophorella) crenulus sp. nov.

22 - Lateral view of adult; 23 - Prodorsum; 24 - Notogastral seta; 25 - Bothridium and sensillus; 26 - Rutellum; 27 - Epimeral region; 28 - Chelicera; 29 - Genital and ano adanal region; 30 - Padipalp; 31 - Leg 1 
Setae cha and chb smooth and pointed. Pedipalp (Fig. 30) with a chaetotaxy of 2-2-8. Epimeral setal formula 1-0-1-1 (Fig. 27), seta of first epimere double the size of the others. All setae thin and pointed. Genital plate rectangular, carrying a broad aggenital plate anteriorly, which bears a minute aggenital seta $a g$ at its outer corner. Genital setae $g_{1}-g_{5}$ minute and very closely arranged along the anterior inner margin while $g_{6}-g_{9}$ longer and arranged at equal distance along the inner margin of the genital plate (Fig. 29). Anoadanal plate broader at the anterior region, almost conical towards the posterior region, carrying three pairs of anal and two pairs of adanal setae. Seta $a d_{1}$, long and foliate while $a d_{2}$ spiniform. Anal setae closely arranged, thin and long with pointed tip. Integument of anoadanal plate finely punctated.

Legs: All legs monodactylous with a thick claw. Chaetotaxy of legs reduced. Chaetotaxy of leg I (Fig. 31) 1:3:3:4:15. Trochanter I with a long thin, smooth seta. Femur I carries three setae, seta $d$ thin and long, $v$ ' slightly barbed. Genu carries two solenidia, a long $s_{\mathrm{I}}$ and a short $s_{2}$. Tibia bears four setae including solenidion $j$. Tarsus bears fifteen setae including three solenidia $w_{1}, w_{2}$, and $w_{3}$. Famulus $e$ seen closely associated with $w_{1}$. Seta $s$ absent. Claw thick and stout with a spinous projection at the base ventrally.

\section{Remarks}

A detailed examination of the morphological features of the present species with the known species of the genus Atropacarus (Hoplophorella) helped to detect its similarity with A. (H.) glaucus described by Hammer (1972) in

(i) Spoon shaped notogastral setae

(ii) Disposition of genital setae $g_{6}-g_{9}$

(iii) Long and pointed nature of anal setae

(iv) Foliate nature of $a d_{1}$ and

(v) In the absence of seta $s$ on tarsus I

But on the basis of the following specific characters, it differs from $A$. glaucus and hence been assigned to a new taxonomic status.

(i) Presence of crossed longitudinal striations on prodorsum.

(ii) Thick nature of seta ro.

(iii) Elongated nature of seta le

(iv) Bare nature of notogastral setae

\section{Atropacarus (Hoplophorella) calotropicus sp. nov.} (Figs. 32-43)

\section{Material Examined}

Holotype: Female, 03.viii.2001, Calicut University Campus, Kerala India, coll. Alphonsa Xavier.

Paratype: 4 females and 1 male, from the decomposed root of Calotropis gigantea.

\section{Etymology}

Species name relates to Calotropis gigantea, the plant with which the species is associated.

\section{Diagnosis \\ Colour: Yellowish-brown.}

Prodorsum (Figs. 32 \& 33): Length - 232 (Range 218-242); width - 108 (Range 104-116). Prodorsum oblong with rounded rostral apex and without lateral carina. Seta ro thick 22 in length with a definite inward bent and a few fine barbs, inserted quite away from rostral apex. Seta le the largest among the prodorsal setae, measuring 44, lanceolate and smooth. Seta in small, smooth and spine like measuring 11 and inserted in between le and bo. Seta ex minute and placed posterior to bo. Sensillus elongate, proximal two third very narrow while the distal one third highly expanded with a crenulated anterior margin (Fig. 34). Bothridium cup shaped with a wide anteriorly directed opening through which emerges the ss. Prodorsum exhibits wrinkled ornamentation along the lateral side, feeble punctations medially and varying number of vertical striations posteriorly (Fig. 33).

Notogaster (Fig. 32): Length - 384 (Range 368-396); width - 300 (Range 292-312). Notogaster densely foveolate, more towards the mid-dorsal region. Fifteen pairs of notogastral setae, setae $c_{1}, d_{1}$ and $e_{1}$ (Fig. 35) of uniform width with inward bent while the rest spoon shaped with short basal portion and with medial thickening (Fig. 36). Seta $d_{1}$ longest (44), $p s_{1}$ shortest (22), others more or less of same length.

Ventral region: Rutellum (Fig. 37) broad and stout with three well developed notches, central notch smaller than the other two. Chelicerae (Fig. 38) stout and punctate, setae cha and chb smooth. Pedipalp (Fig. 37) with a chaetotaxy of 2-2-9. Infracapitulum (Fig. 37) bears three setae, $a, h$, and $m$, all setae smooth and almost of the same length. Gnathosomal integument with fine punctations. Epimeral setal formula 1-0-1-1 (Fig. 39). Setae of epimere 1 foliate and longer while those of 3 and 4 thin and pointed towards tip. Genital plate (Fig. 40) rectangular in outline carrying the broad aggenital plate anteriorly. A small aggenital seta, $a g$ seen at the outer corner of each aggenital plate. Genital setae $g_{1}-g_{3}$ closely arranged, $g_{4}-g_{9}$ visible clearly, arranged in a row towards the inner margin. All setae small and smooth. Genital plates ornamented with fine punctations. Anoadanal plate (Fig. 40) rectangular like the genital plate and almost of the same length. Three pairs of anal and two pairs of adanal setae present. Anal setae of equal length, smooth with pointed tip (Fig. 41), $a d_{1}$ long and foliate (Fig. 42), $a d_{2}$ smaller, smooth with pointed tip. Integument of anoadanal plate provided with wrinkles along the lateral and posterior periphery.

Legs: All legs monodactylous with a thick empodial claw on each tarsal segment. Chaetotaxy of leg I (Fig. 43) 1-4-3-6-16. Seta of trochanter I thin and smooth with fine tip. Femur I with four setae with varying degrees of barbation. Genu I carries two solenidia $s_{1}$ and $s_{2}$, the latter twice longer than the former. Tibia I carries a single solenidion $\mathrm{j}$. Seta $d$ very small and seen in close association with the solenidion. Setae $l$ ' and $l$ "' smooth, $v$ ' and $v$ " with fine barbs. Tarsus I with 16 setae. Of the three solenidia, $w_{2}$ and $w_{3}$ of equal length, $w_{1}$ smaller. Famulus $(e)$, smooth and pointed. Claw on tarsus I stout with rounded apex bearing two spinous teeth ventrally towards the base. 

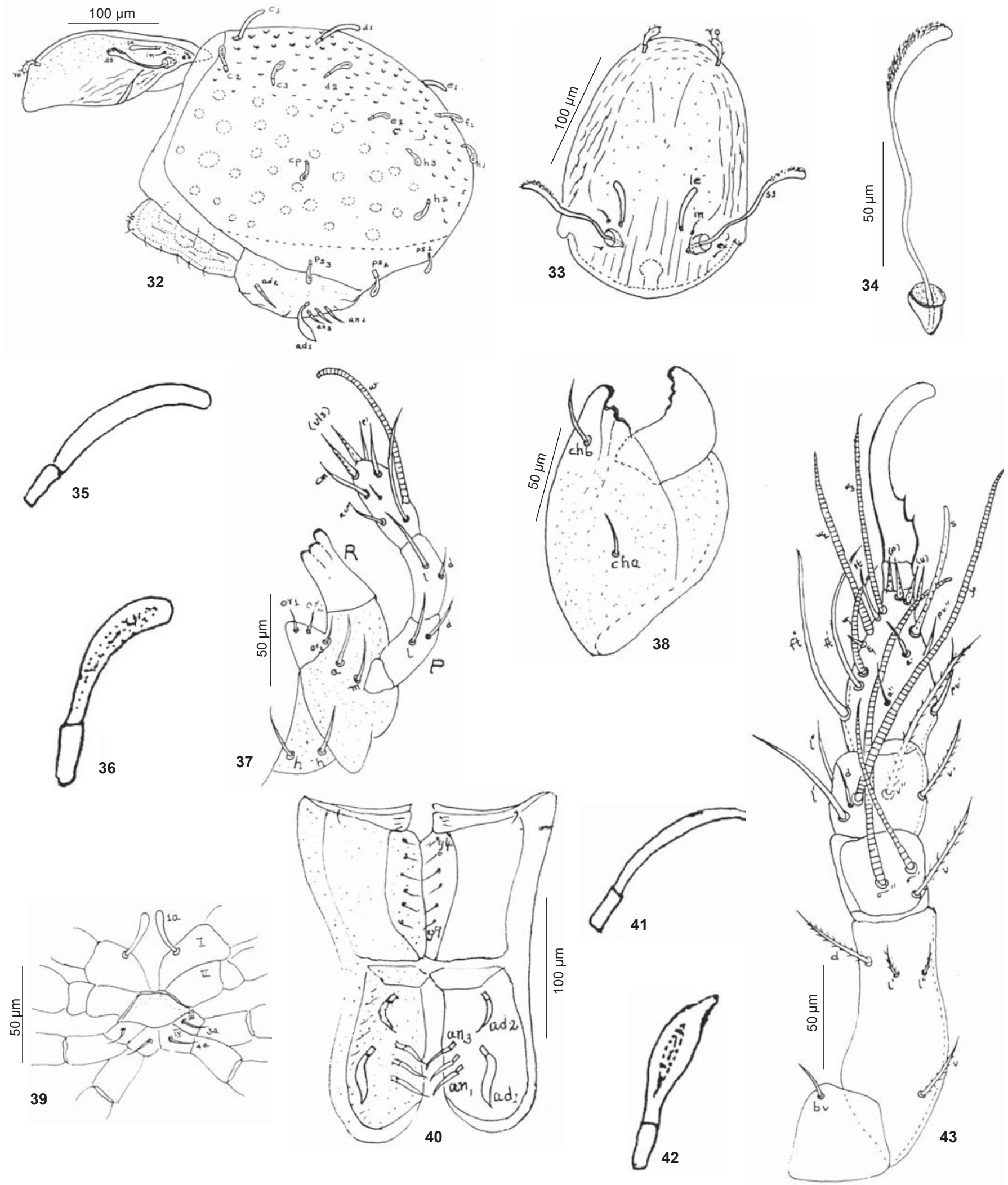

Figures 32-43. Atropacarus (Hoplophorella) calotropicus sp. nov.

32 - Lateral view of adult; 33 - Prodorsum; 34 - Bothridium and sensillus; 35 - Notogastral seta ; 36 - Pedipalp;

37 - Infracapitulum; 38 - Chelicera; 39 - Epimeral region; 40 - Genital and ano adanal region; 41 - Anal seta; 42 - Adanal seta; 43 - Leg 1 


\section{Remarks}

A comparison of the present species with other described species of the genus Atropacarus reveals its resemblance to $A$. (H.) rangiroaensis (Hammer, 1972) in the following features:

(i) Absence of lateral carina.

(ii) Spoon shaped setae of notogaster.

(iii) Distally expanded nature of sensillus.

(iv) Slender nature of $a d_{2}$

(v) Long and comparatively thick nature of anal setae.

But the present species can be easily distinguished from $A$. rangiroaensis by the following characters.

(i) Foveolate nature of integument.

(ii) Barbed nature of seta ro

(iii) Foliate nature of setae $c_{l}, d_{1}$ and $e_{l}$, with uniform thickness.

(iv) Arrangement of genital setae.

The above characters enable to assign the present species to a new taxon.

\section{REFERENCES}

Aoki, J. (1965). Oribatiden (Acarina) Thailands 1. Natural Life Southeast Asia, Kyoto 4: 129-193.

Aoki, J. (1980). A revision of the oribatid mites of Japan. Bulletin of the Institute of Environmental Science and Technology, Yokohama National University 6(2): 1-89.

Balogh, J. (1958). Oribatides nouvelles de l'Afrique tropicale. Revue Suisse de Zoologie Botany 58(1-2): 1-34.

Dinsdale, D. (1974). Feeding activity of a phthiracarid mite (Arachnida: Acari). Journal of Zoology 174: 15-21.

Edsberg, E. and S. Hagvar (1999). Vertical distribution, abundance and biology of oribatid mites (Acari) developing inside decomposing spruce needles in a podosol soil profile. Pedobiologia 43(5): 413-421.

Ewing. H.E. (1909). New American Oribatoidea. Journal of New York Entomology Society 17(3): 116-136.

Hammer, M. (1961). Investigations on the oribatid fauna of the Andes Mountains. II. Peru. Biologiske Skrifter Det Kongeliege Danske Videmskabernes 13: 1-157.

Hammer, M. (1972). Investigations on the oribatid fauna of Tahiti and on some oribatids found on the atoll Rangiroa. Biologiske Skrifter Det Kongeliege Danske Videmskabernes 19(3): 1-65

Haq, M.A. (1984). The role of mircrobes in the nutrition of a lohmanniid mite (Acari: Oribatei), pp.819-825. In: Griffiths, D.A. and C.E. Bowman (Eds.). Acarology VI (2). Ellis Horwood Ltd., Chichester, England.

Haq, M.A. (1987). Biodegradation of cellulose in the gut of Heptacarus hirsutus Wallwork, 1964 (Acari, Oribatei), pp. 93-98. In: Striganova, B.R. (Ed.). Soil Fauna and Soil Fertility. Nauka, Moscow.

Haq, M.A. (2003). Bioprocessing of plant litter by oribatid mites in tropical ecosystem. pp. 1-33. XI International Congress of Acarology, National Autonomous University, Mexico, USA. (in print).

Haq, M.A. and I.D. Konikkara (1988). Microbial association in xylophagous oribatids, pp.483-489. In: Channa Basavanna, G.P. and C.A. Virakthamath (Eds.). Progress in Acarology (1). Oxford and IBH Publishing Co. Pvt. Ltd., New Delhi.

Jacot, A.P. (1933). Phthiracarid mites of Florida, Journal of Elisha Mitch. Science Society Chapel Hill, 48(2): 232-267

Mahunka, S. (1978a). Neue und interessante Milben aus dem Genfer Museum XXVIII. A first survey of oribatid (Acari) fauna of Mauritius, Reunion and the Seychelles Is. Revue Suisse de Zoologie 85(1): 177236.

Mahunka, S. (1978b). Neue und interessante Milben aus dem Genfer Musueum XXXIV. A compendium of the oribatid (Acari) fauna of Mauritius, Reunion and the Seychelles As. II, Revue Suisse de Zoologie 85(2): $307-340$.
Niedbala, W. (1981). Trois nouveaux Phthiracaridae (Acari: Oribatida) originaires du Bresil, Acarologia, Abbeville 23(1): 63-80.

Niedbala, W. (1983a). Trois nouvelles especes du genre Hoplophorella (Acari: Oribatida: Phthiracaridae) due Kenya, Buletin de la Societe des Amis. Sciences Et Des. letters 22: 127-141.

Niedbala, W. (1983b). New Phthiracaridae of Uganda (Acari: Oribatida) Folia Entomology Hungary 44(1): 109-124.

Niedbala, W. (1984). Hoplophorella neglecta sp. nov. (Acari: Oribatida Phthiracaridae) du Perou, Buletin de la Societe des Amis. Sciences Et Des. letters 24: 133-137.

Sanyal, A.K. and A.K. Bhaduri (1981). A new species of the Genus Hoplophorella (Acari: Oribatei) from West Bengal, India. Indian Journal of Acarology 6: 35-38.

Sellnick, M. (1959). Acarina from South eastern Polynesia-II (Oribatidae), Occasional Paper of the Bishop Museum, Honolulu 22(9): 109-152.

Wallwork, J.A. (1967). Some oribatei (Acari: Cryptostigmata) from Tchad. Revue Suisse de Zoologie Africa 75: 35-45.

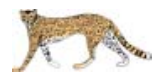

\section{Volunteers needed}

The Chiroptera Conservation and Information Network of South Asia (CCINSA) along with Dr. Shahroukh Mistry, USA, have embarked on a project that involves identification and monitoring of fruit bat (Pteropus giganteus) colonies/roosts all over South Asia. The project will be an ongoing one with regular monitoring of colonies to understand the dynamics, population trends and various other aspects of the region's largest bats.

If you or any one of your colleagues or friends are interested in joining this exciting project, please write with your name, address, occupation, interest in this subject, and the geographical area you would like to participate in monitoring fruit bats.

We already have a few volunteers who have started work in different parts of South Asia. South Asia is a large region and we need many more people.

Write to us at the earliest to be part of this longterm, first of its kind project:

\section{Ptero Count}

Sanjay Molur / Sally Walker / Sripathi Kandula (Scientific Chair), CCINSA

Zoo Outreach Organisation, 29-1 Bharathi Colony, Peelamedu, Coimbatore, Tamil Nadu 641004, India

Email: herpinvert@vsnl.com, zooreach@vsnl.com;

Ph: +91 422 2568906, 2561743, 2561087;

Fx: +914222563269 